\title{
A Phenomenological Study on the Synergistic Role of Precious Metals in the Steam Reforming of Logistic Fuels on Bimetal-Supported Catalysts
}

\author{
Abdul-Majeed Azad and Desikan Sundararajan \\ Chemical Engineering Department, The University of Toledo, 2801 W. Bancroft Street, Toledo, OH 43606-3390, USA \\ Correspondence should be addressed to Abdul-Majeed Azad, Abdul-Majeed.Azad@Utoledo.Edu
}

Received 10 March 2011; Accepted 25 May 2011

Academic Editor: Markku Leskela

Copyright ( 2011 A.-M. Azad and D. Sundararajan. This is an open access article distributed under the Creative Commons Attribution License, which permits unrestricted use, distribution, and reproduction in any medium, provided the original work is properly cited.

Fuel processors are required to convert sulfur-laden logistic fuels into hydrogen-rich reformate and deliver to the fuel cell stack with little or no sulfur. Since sulfur poisons and deactivates the reforming catalyst, robust sulfur-tolerant catalysts ought to be developed. In this paper, the development, characterization and evaluation of a series of reforming catalysts containing two noble metals (with total metal loading not exceeding 1 weight percent) supported on nanoscale ceria for the steam-reforming of kerosene is reported. Due to inherent synergy, a bimetallic catalyst is superior to its monometallic analog, for the same level of loading. The choice of noble metal combination in the bimetallic formulations plays a vital and meaningful role in their performance. Presence of ruthenium and/or rhodium in formulations containing palladium showed improved sulfur tolerance and significant enhancement in their catalytic activity and stability. Rhodium was responsible for higher hydrogen yields in the logistic fuel reformate. Duration of steady hydrogen production was higher in the case of RhPd (75h) than for RuPd (68 h); hydrogen generation was stable over the longest period $(88 \mathrm{~h})$ with RuRh containing no Pd. A mechanistic correlation between the characteristic role of precious metals in the presence of each other is discussed.

\section{Introduction}

In the light of the recent quest for cleaner and greener energy, fuel cells running on hydrogen feeds derived from abundant logistic fuels are attractive options, provided strategies for effective desulfurization and sustained reforming via robust sulfur-tolerant catalysts are in place. Use of hydrogen-rich reformates of logistic fuels such as Avgas (aviation gasoline), JP-5, JP-8, and Jet-A as the feed for SOFCs, is appealing to NASA and Department of Defense.

However, the catalysts used for reforming heavy hydrocarbons are poisoned by sulfur present in logistic fuels. During reforming process, sulfur gets transformed into $\mathrm{H}_{2} \mathrm{~S}$ and if not removed effectively, even $1 \mathrm{ppm}$ or less in the reformate could deactivate the SOFC anode rapidly [1]. Thus, fuel processors are required to convert logistic fuels into hydrogen-rich reformate for extended periods and deliver hydrogen with little or no sulfur to the fuel cell stack. In order to facilitate continuous uninterrupted operation of logistic fuel processors, robust sulfur tolerant catalysts are sought.

A systematic investigation was undertaken to understand and elucidate the role of precious metals in imparting sulfur tolerance to the nanoscale ceria-based reforming catalysts in the process of hydrogen generation via steam reforming. The active metal dispersion in these sulfur-tolerant catalyst formulations was varied between 1 and $1.33 \mathrm{wt} . \%$. The formulations contained either one, two, or three precious metals. These formulations were assessed in terms of their sulfur tolerance, phase integrity, and the quality of reformate from kerosene (JP-8 surrogate) fuel at temperatures typically employed in reforming. The performance of single metalsupported nanocatalysts in the steam reforming of a JP- 8 surrogate fuel (kerosene) containing $260 \mathrm{wppm}(260 \mathrm{mg} \mathrm{S} / \mathrm{kg}$ fuel) was recently reported [2]. As a result of this investigation, several multifunctional aspects of these formulations become evident. Some of the key features included their 
effectiveness in hydrogen generation in terms of high yield and long-term stability on-stream and the crucial role of the ceria support in rendering the catalyst sulfur tolerant. Furthermore, the reason of catalyst deactivation appeared to be mainly due to sulfur poisoning rather than carburization (coke formation). In addition, the catalysts were capable of in situ methanation; this was verified by theoretical calculations which corroborated the experimental data on carbon balance.

This communication highlights the performance of bimetal-supported ceria nanocatalysts in terms of hydrogen yield and sulfur tolerance as a function of time on stream.

The rationale behind the choice of nanoscale ceria as support material in this work is due to its unique characteristics as opposed to the traditional supports. There, a great deal of rationale for using ceria supports in the present work. Ceria is commercially used in catalytic converters as a support for three-way catalyst for reducing harmful emissions from automobiles [3]. It is well known for its high oxygen storage capacity (OSC) and easy reducibility due to its facile Ce ${ }^{\mathrm{III}} \leftrightarrow$ $\mathrm{Ce}^{\mathrm{IV}}$ equilibrium; $\mathrm{CeO}_{2}$-based materials are quite active and stable both in reducing and oxidizing atmospheres in hightemperature regimes compared to other conventional support systems [4-7]. This, in conjunction with a preparative technique that provides nanoscale particles, results in a highsurface-area catalyst with the possibility of high activity for the reforming of sulfur-laden fuels. When used as a support for precious metal(s), it results in the transfer of oxygen to the supported metals while the support is then reoxidized by the water present in the steam reforming reaction. Increased OSC leads to increase in oxygen vacancies which contribute to increased reducibility of ceria as well. Although, $\mathrm{CeO}_{2}$ is more active as a reforming catalyst than $\mathrm{Ce}_{2} \mathrm{O}_{3}$, it can act beneficially towards sulfur tolerance as will be shown later.

Thermodynamically, in a reducing environment, $\mathrm{Ce}_{2} \mathrm{O}_{3}$ has higher sulfidation equilibrium constant than $\mathrm{CeO}_{2}$, suggesting a possibility of formation of either cerium oxysulfide (partial sulfidation) or cerium sesquisulfide (complete sulfidation). This mechanism might help mitigate sulfurmediated poisoning and deactivation of ceria-based catalysts in the long run. This sacrificial role may also allow precious metal(s) to remain active longer, resulting in better catalyst life. Furthermore, $\mathrm{H}_{2} \mathrm{~S}$ adsorption on ceria is partially reversible. The thermodynamics of the $\mathrm{CeO}_{2}-\mathrm{H}_{2} \mathrm{~S}$ reaction, however, do not allow the reduction of $\mathrm{H}_{2} \mathrm{~S}$ to below $200 \mathrm{ppm}$ at about $627^{\circ} \mathrm{C}$; even at a temperature of $827^{\circ} \mathrm{C}$, the $\mathrm{H}_{2} \mathrm{~S}$ level cannot be reduced to below $100 \mathrm{ppm}$. This requires ceria to be in a reduced form $\left(\mathrm{CeO}_{n} ; n<2\right)$ to achieve the removal of sulfur to desired levels. Upon reduction, $\mathrm{CeO}_{2}$ goes to $\mathrm{Ce}_{2} \mathrm{O}_{3}$, thereby creating oxygen ion vacancies, and thus sulfidation of ceria occurs rapidly. In the light of these characteristics, ceria was used as a support matrix for the development of sulfur-tolerant catalytic formulations [8-10].

The bimetal dispersion on nanoscale ceria support proved to be superior to its mono-metal analog, in terms of the longevity of the steady-state, hydrogen yield and sulfur tolerance, under identical experimental conditions. A plausible mechanistic correlation between the synergistic role of precious metals in presence of one another and the behavior of the catalysts in terms of the above-mentioned features is suggested.

\section{Experimental Details}

Nanoscale support material consisting 10 mole \% gadolinia $\left(\mathrm{Gd}_{2} \mathrm{O}_{3}\right)$-doped $\mathrm{CeO}_{2}$ - hereafter referred to as GDC-was synthesized via ammonia precipitation using appropriate water soluble precursors for cerium and gadolinium (from Alfa-Aesar, Mass USA) followed by hydrothermal treatment of the basic slurry USA thus obtained in an autoclave at $240^{\circ} \mathrm{C}$, for $2 \mathrm{~h}$. The resulting material was dried overnight and systematic structural and morphological characterizations were carried out to follow the crystallization and phase evolution pathways as a function of calcination temperaturetime profile.

The catalysts were formulated by dispersing precious metals - two at a time-onto the GDC support material, using their respective water soluble precursors: ruthenium (III) chloride (99.999\%), palladium (II) nitrate (99.95\%), rhodium (III) nitrate hexahydrate (99.999\%) (all from AlfaAesar, Mass, USA). For this purpose, aqueous slurry of GDC and the precious metal precursors were homogenized in a rotary evaporator for $4-6 \mathrm{~h}$ and the thickened mass was dried overnight in a vacuum oven at $100^{\circ} \mathrm{C}$. The dried cake consisting of soft agglomerates was crushed using mortar and pestle and pulverized in a ball mill using 2-propanol and $5 \mathrm{~mm}$ diameter zirconia media. The ball-milled slurry was dried again under ambient conditions and sieved through 325 mesh screen. Each formulation was calcined in air at $700^{\circ} \mathrm{C}$ for $2 \mathrm{~h}$. These formulations contained $(1 / 2 \mathrm{wt} \% \mathrm{Ru}$ $+1 / 2 \mathrm{wt} \% \mathrm{Pd})$ in one case, $(1 / 2 \mathrm{wt} \% \mathrm{Ru}+1 / 2 \mathrm{wt} \% \mathrm{Rh})$ in the second, and $(1 / 2 \mathrm{wt} \% \mathrm{Pd}+1 / 2 \mathrm{wt} \% \mathrm{Rh})$ in the third case. They will be referred to as RuPd, RuRh, and RhPd, respectively, throughout the paper.

The catalysts were characterized by a host of techniques with respect to their crystallinity, active metal dispersion, structural and morphological features. Temperature programmed reduction (TPR) of the as-prepared reforming catalysts was conducted using the Micromeritics AutoChem 2910 (Norcross, Ga,USA) to optimize a systematic activation protocol for each catalyst prior to sulfidation and reforming experiments.

Independent sulfidation experiments were carried out by introducing $1000 \mathrm{ppm}_{2} \mathrm{~S}$-balance nitrogen stream over a bed of $1 \mathrm{~g}$ of powder catalyst at $800^{\circ} \mathrm{C}$ for 4 and $24 \mathrm{~h}$. X-ray powder diffraction (XRD) signatures on the as-prepared and postsulfided samples were collected on a Philips diffractometer (PW 3050/60 X'pert Pro), using monochromatic $\mathrm{CuK} \alpha_{1}$ radiations $(\lambda=1.54056 \AA)$ and $\mathrm{Ni}$ filter. The total amount of sulfur retained by the catalysts was quantified by wet chemical techniques by NSL Analytical, Cleveland, Ohio, USA.

Steam-reforming experiments were carried out on powder samples $(1 \mathrm{~g})$ using kerosene as the fuel. LC-MS test established the sulfur content of this kerosene sample to be $260 \mathrm{ppm}$ as determined by Paragon Laboratories, Mch, USA. The packed bed reactor used here was a quartz tube, 19 in long and 1 in OD. The catalyst was packed in a stainless 
steel filter with $5 \mu \mathrm{m}$ size pore from Swagelok ${ }^{\mathrm{TM}}$. The filter containing the catalyst was placed in the center of the reactor and plugged with loosely packed quartz wool. The quartz reactor was then placed in a 1 in. split tube furnace equipped with a PID controller.

Water and fuel (kerosene) were pumped into the reactor with ChromTech, Inc. ISO-100 high precision HPLC pumps. Argon was used as a sweep gas for the reforming reaction. The steam to carbon ration $(\mathrm{S} / \mathrm{C})$ was maintained at 3 . The flow rates of water and fuel were adjusted to maintain a constant space velocity in the reactor at $65,000 \mathrm{~h}^{-1}$. The feed stream containing sweep gas, water, and fuel was first introduced into a preheater (vaporizer furnace) operated at $250^{\circ} \mathrm{C}$ to ensure complete vaporization of the feed. All reforming reactions were carried out at $800^{\circ} \mathrm{C}$. The product stream coming out of the reactor was drawn into a condenser to separate the liquid and gas products. The liquid fraction consisted mainly of water and unreacted fuel with traces of other liquid hydrocarbons. The composition of the gas reformate mixture was analyzed via Gas Chromatograph (GC). Shimadzu GC, Model 2010 equipped with pulsed discharge helium ionization detector (PDHID) and flame photometric detector (FPD), was used to analyze the gas products. The FPD on the GC was facile in detecting sulfur species in the reformate stream. The duration of the experiment was determined by the stability and activity exhibited by the catalysts on stream. The hydrogen yield was defined as

$$
\% \text { yield }=\frac{\left(F_{i}\right)}{\left(v_{i}\right) \cdot\left(F_{j, 0}\right)} * 100 \text {, }
$$

where $F_{i}$ is the moles of species $i$ produced per min, $v_{i}$ is the stoichiometric coefficient of species $i$, and $F_{j, 0}$ is the molar flow rate of the reactant in moles/min.

The GC was calibrated with respect to hydrogen, carbon monoxide, carbon dioxide, and methane-the major constituents in a typical reformate-over a wide range of concentrations. GC was also calibrated with respect to $\mathrm{H}_{2} \mathrm{~S}$ concentration between zero and $1000 \mathrm{ppm}$. The reforming was conducted over extended period of time. It was terminated as per an arbitrarily selected criterion of hydrogen yield reducing to $20 \%$ or the sulfur level reaching $50 \mathrm{ppm}\left(\right.$ as $\left.\mathrm{H}_{2} \mathrm{~S}\right)$ in the exit stream. Concentration of other gases was also monitored simultaneously as a function of time.

Systematic microstructural analysis was performed by scanning electron microscopy (SEM-Phillips XL 30 FEG) and transmission electron microscopy (TEM-JEOL 3011). Both of these techniques are equipped with the capability of performing energy dispersive X-ray spectroscopy (EDS) as well. The SEM is equipped with Rutherford's back scattering electron mapping (RBSE) as well. The chemical state analysis of the active components in the postreformed samples was performed by using X-ray photoelectron spectroscopy on the Kratos Axis Ultra XPS.

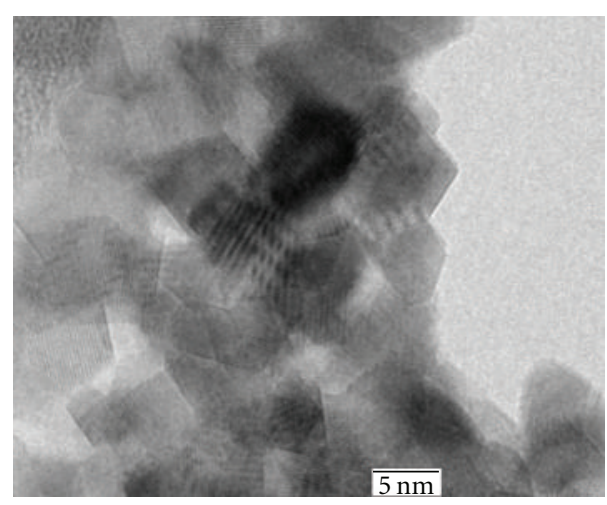

(a)

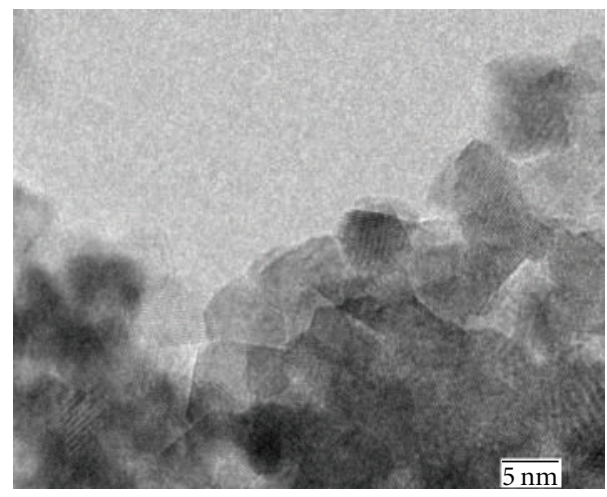

(b)

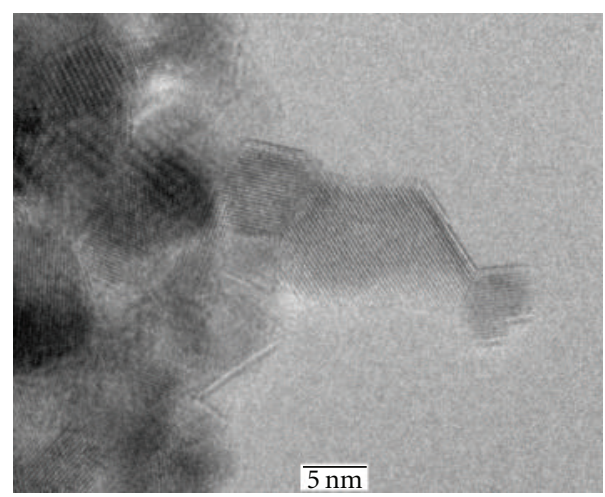

(c)

FIGURE 1: TEM images of the as-prepared catalysts. (a) RuPd, (b) RuRh, and (c) RhPd.

\section{Results and Discussion}

3.1. Structural and Microstructural Artifacts of the Precious Metal-Supported Nanocatalysts. The TEM images of the asprepared bimetal catalysts are shown in Figure 1; clearly all formulations possess nanofeatures. The contrasting light and dark particle contours in these images belong to the GDC support and the noble metals, respectively. This further suggests that despite low concentration, the dispersion of the noble metals is highly uniform throughout the matrix.

Thus, the preparatory technique utilized for making them is quite effective in yielding uniform distribution of the precious metals throughout the support. 


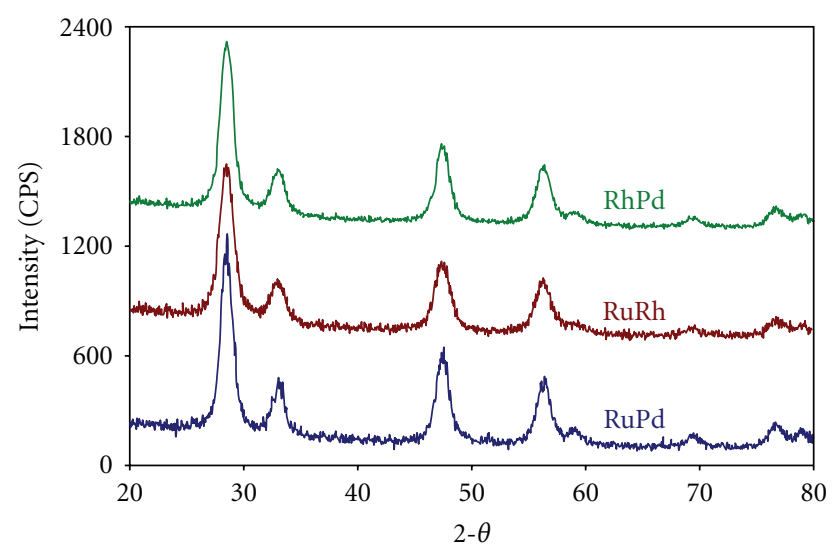

FIGURE 2: XRD signatures of the bimetal supported catalysts calcined at $700^{\circ} \mathrm{C}$ for $2 \mathrm{~h}$.

The nanofeatures observed in the TEM images are corroborated by the broad diffraction peaks in the XRD patterns of the powders calcined at $700^{\circ} \mathrm{C}$ for $2 \mathrm{~h}$, as shown in Figure 2.

The gross XRD patterns are typical of those for 10 mole $\%$ gadolinia-doped ceria (GDC) used in this work [11]. Peaks for the precious metals are not discernable due to their low loading ( $1 \mathrm{wt} . \%)$, which is below the detection limit of the XRD technique. Estimation of the crystallite size using Scherrer's equation, yielded values between 5 and $8 \mathrm{~nm}$, which is in excellent agreement with those seen in the TEM images. These nanofeatures ensure large surface area and effective noble metal dispersion, thereby lowering the loading; this keeps the manufacturing cost low without compromising the performance.

3.2. Propensity to Sulfur Tolerance. Recent studies have shown irreversible sulfur poisoning to be the main cause of deactivation of reforming catalyst in the case of logistic fuels [1], making it imperative that the catalysts designed for the reforming of sulfur-laden fuels be evaluated for their sulfur tolerance first. Therefore, as was done in the case of monometal supported formulations [2], the bimetal catalysts were also examined for their sulfur tolerance and phase integrity under conditions of sulfur exposures for extended period. Packed beds of the catalyst powders $(1 \mathrm{~g})$ were

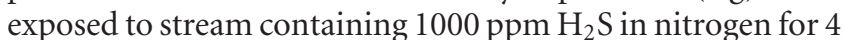
and $24 \mathrm{~h}$, and the postsulfided samples were analyzed for sulfur pick-up. The results of $24 \mathrm{~h}$ soak are presented in Figure 3.

The trend of sulfur pickup by these formulations showed an interesting pattern. First and foremost, as expected, it is proportional to the soak time. Second, the amount of sulfur sorbed by bimetallic series is considerably lower than that in the case of mono-metal dispersions. For example, it was found that Ru-bearing catalyst picked up $2000 \mathrm{ppm}$ while those containing Pd or Rh sorbed 2610 and 2190 ppm, respectively. In the case of mono-metal formulations, it was found that [2] ruthenium-based formulation exhibited highest sulfur tolerance followed by the rhodium analog; palladium-based formulation was most susceptible to sulfur

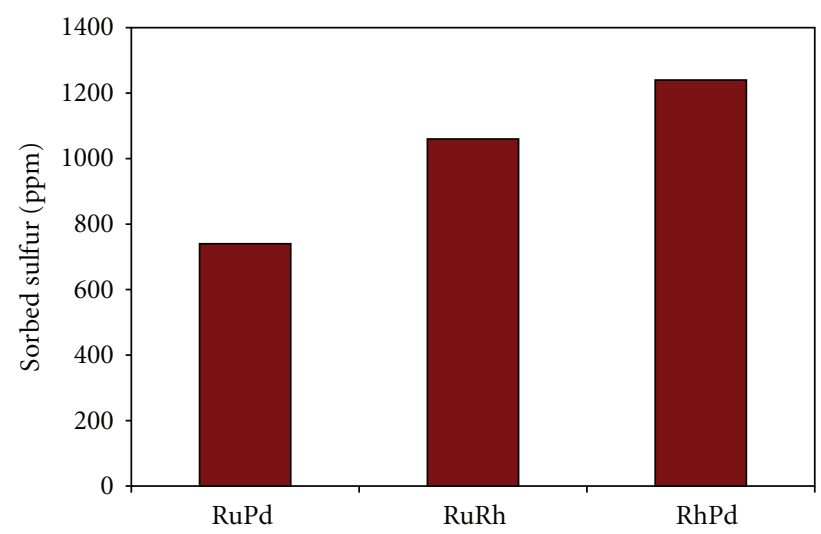

FIGURE 3: Sulfur-sorption characteristics of bimetallic catalysts during $24 \mathrm{~h}$ soak at $800^{\circ} \mathrm{C}$ in $1000 \mathrm{ppm} \mathrm{H}_{2} \mathrm{~S} / \mathrm{bal} . \mathrm{N}_{2}$ ambient.

poisoning, meaning that the sulfidation susceptibility followed the pattern: $\mathrm{Ru}<\mathrm{Rh}<\mathrm{Pd}$.

Figure 3 amply demonstrates that similar trends were evident in bimetallic formulations as well. Thus, the RhPd formulation exhibited the highest sorption, while RuPd sorbed the lowest, with RuRh falling in between. If this is any guideline, then in terms of reforming of a sulfurladen fuel, this might mean that the lowest and the highest sulfur tolerance would be exhibited by RuPd and RhPd, respectively. This prediction would be examined later in the light of steam-reforming data obtained with bimetalsupported catalysts.

Figure 4 shows the TEM images of the bimetallic catalysts after sulfidation for $24 \mathrm{~h}$ at $800^{\circ} \mathrm{C}$ in a nitrogen stream containing $1000 \mathrm{ppm}_{2} \mathrm{~S}$.

In order to ascertain that the phase and microstructural integrity of the catalysts under sulfidation conditions is maintained, it was imperative to analyze the postsulfided samples as well. For illustrative purposes, the $\mathrm{XRD}$ signatures of RuPd sulfided for 4 and $24 \mathrm{~h}$ are compared with that of asprepared sample in Figure 5. A comparison of microstructural features shown in Figures 1 and 4, clearly indicates the evidence of grain growth in the samples sulfided for longer $(24 \mathrm{~h})$ duration; the particles have grown to about 7-10 $\mathrm{nm}$ in size, a fact which is corroborated by the peak narrowing seen in the XRD signatures shown in Figure 5.

The peak sharpening is an indication of systematic crystallinity enhancement as a function of time at high temperature. In this case, the peak narrowing is an artifact of grain growth and crystallite size enhancement upon sulfidation. However, the crystallite texture is maintained; the crystallite size calculation and TEM images suggest that the grain growth in the sulfided samples is only minimal, indicating no significant surface area reduction occurred. It can also be seen that no new phases could be discerned, suggesting phase integrity was preserved under sulfidation at high temperatures.

The TEM images taken on RuPd samples after 4 and $24 \mathrm{~h}$ of sulfidation (shown in Figure 6) indicate some agglomeration. 


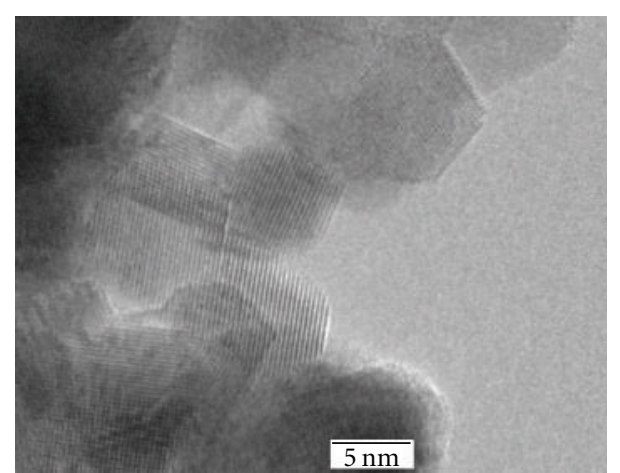

(a)

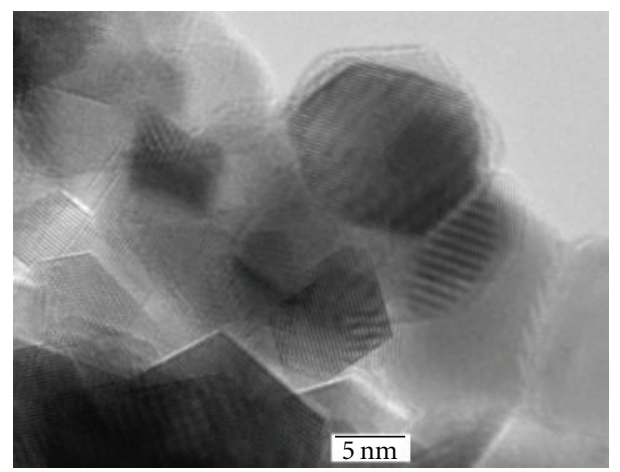

(b)

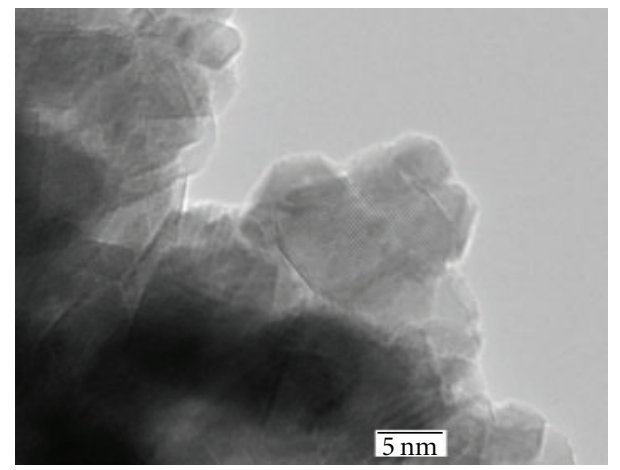

(c)

Figure 4: TEM images of sulfided catalysts. (a) RuPd, (b) RuRh, and (c) RhPd.

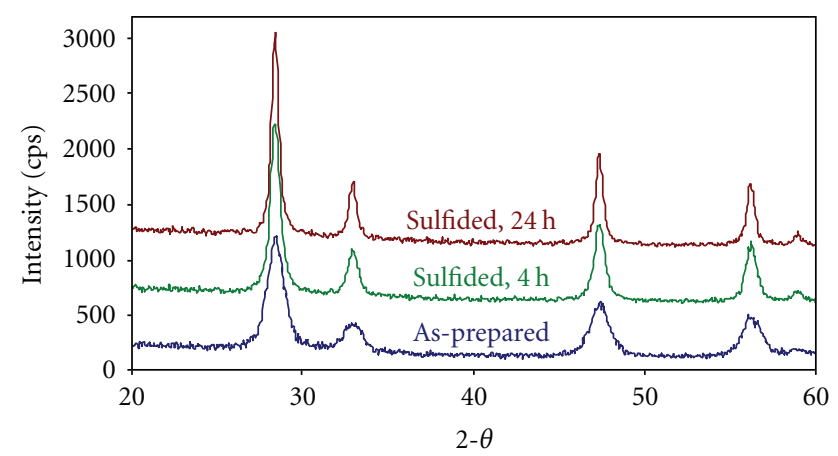

FIgURE 5: Comparative XRD patterns of the unsulfided and postsulfided ( $1000 \mathrm{ppm} \mathrm{H}_{2} \mathrm{~S} / \mathrm{bal}$. $\mathrm{N}_{2}$. at $800^{\circ} \mathrm{C}$ for 4 and $24 \mathrm{~h}$ ) bimetallic powders of the catalyst RuPd.

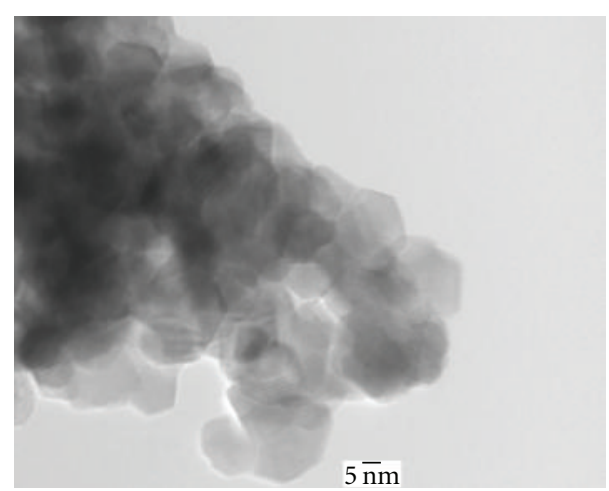

(a)

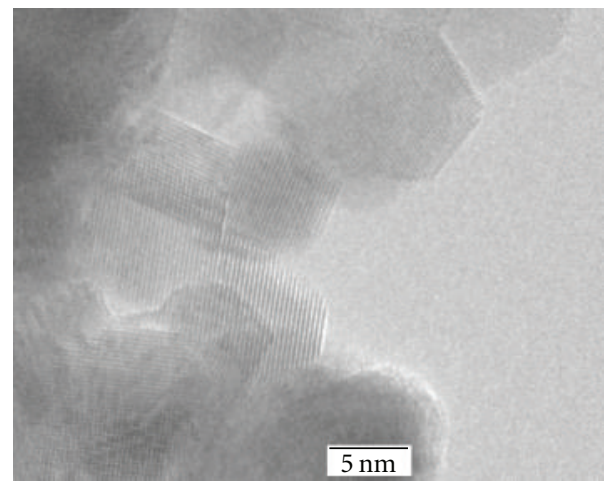

(b)

Figure 6: Evidence of agglomeration in RuPd sulfided for $24 \mathrm{~h}$ (a) compared to $4 \mathrm{~h}(\mathrm{~b})$.

However, the observed grain growth and agglomeration did not adversely affect the reforming performance of these catalysts, as was clearly seen in term of the hydrogen yield or the on-stream life time of these formulations. These aspects are discussed in the following section.

3.3. Steam-Reforming Characteristics. The reforming as well as the sulfidation experiments conducted with the single metal supported nanocatalysts had shown that each noble metal is individually capable of producing hydrogen via steam reforming, albeit to different level [2]. Furthermore, each of them possesses a distinct advantage over the other. In order to combine and, if possible, accentuate these characteristics, bimetallic formulations were developed, keeping the gross loading of the noble metals in each formulation to be $1 \mathrm{wt} \%$, thereby making them more cost effective.

All kerosene steam-reforming experiments were carried out at $800^{\circ} \mathrm{C}$ and atmospheric pressure $(\sim 14.7 \mathrm{psi})$ keeping the steam-to-carbon ratio constant at 3.0. The experiments were terminated when the hydrogen yield reached about $20 \%$ or the sulfur $\left(\right.$ as $\mathrm{H}_{2} \mathrm{~S}$ ) peaked to about $50 \mathrm{ppm}$ in the reformate.

Figure 7 depicts the reformate compositions resulting from the steam reforming of kerosene on three bimetal supported reforming catalysts, as a function of time onstream. 


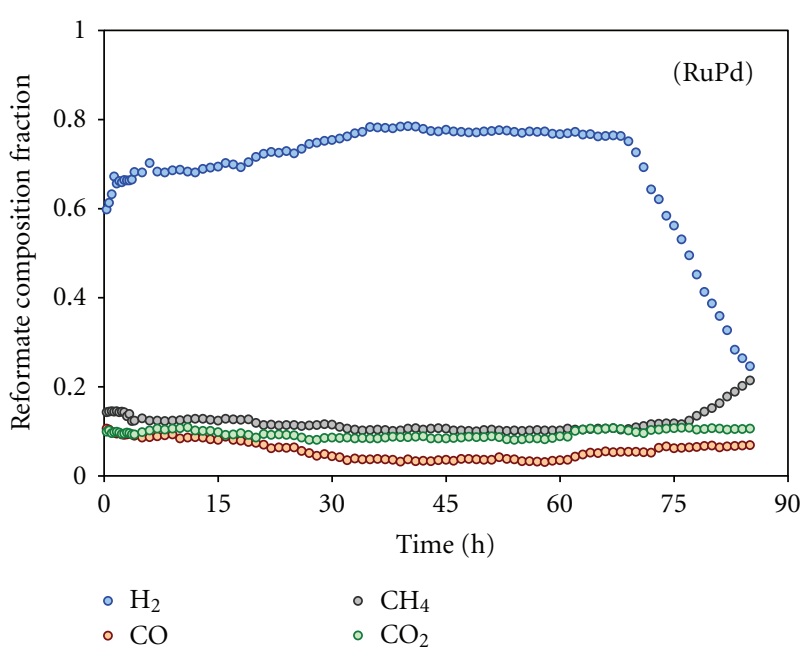

(a)

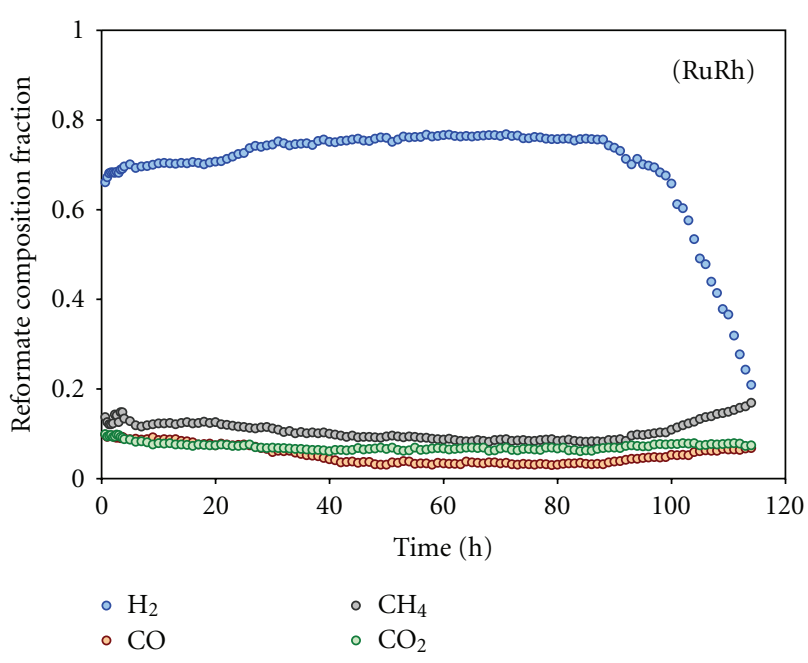

(b)

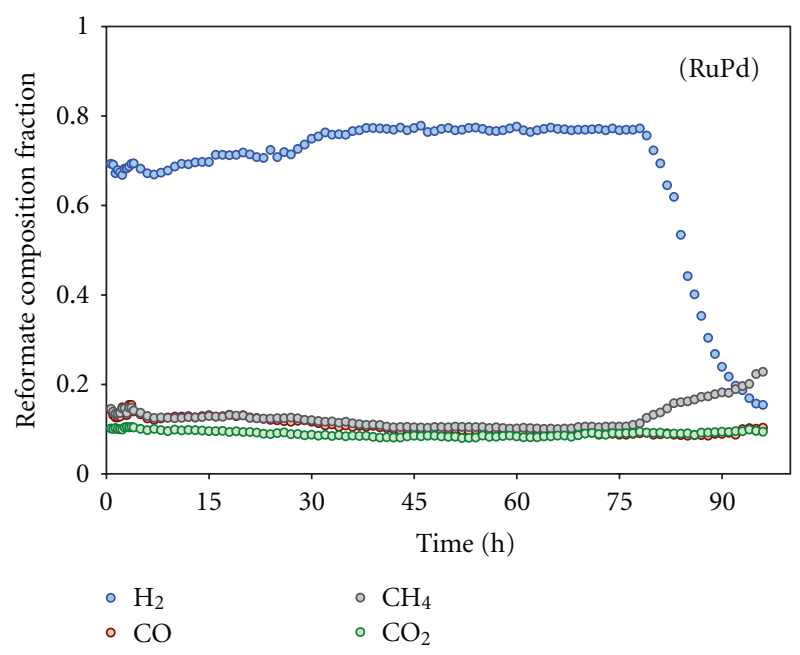

(c)

FIgURE 7: Composition of kerosene reformates with the three bimetallic catalysts.

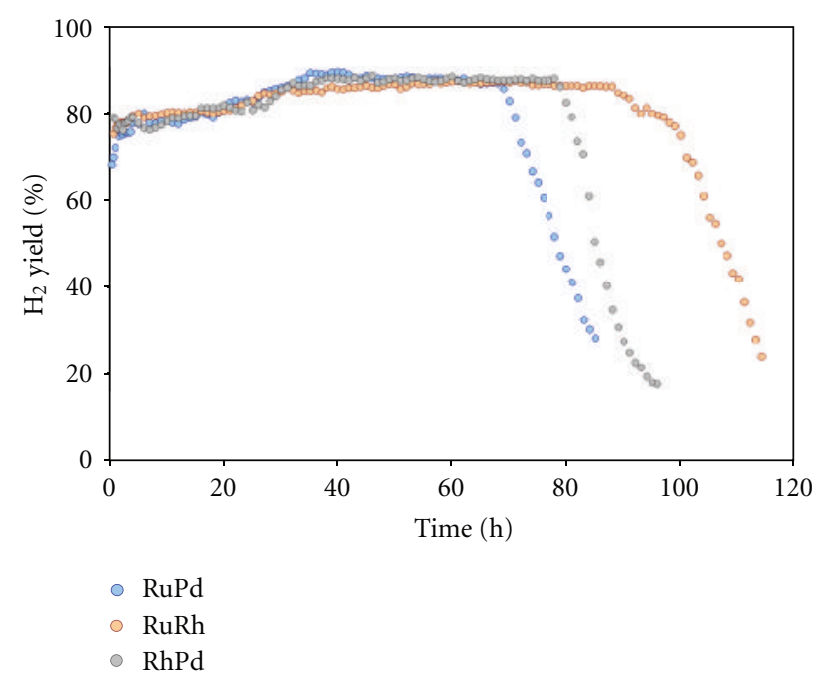

FIGURE 8: Performance of bimetallic catalysts in terms of hydrogen yield.

Evidently, the hydrogen yield with bimetallic formulations is higher than that with the monometal analogs. The performance, in terms of the duration over which hydrogen production was steady, was also superior as seen from the data summarized in Table 1. Moreover, the performance in terms of hydrogen yield is characteristic of the precious metal combination in each of them.

Since it was difficult to determine the exact composition of the fuel, thermodynamic calculations were conducted on a surrogate fuel mixture which comprised $70 \% \mathrm{n}$-hexadecane and $30 \%$ toluene. This composition was chosen based on a similar simulated mixture used by others [12], and equilibrium conversions were estimated by Invensys Pro/II Simulation Software Version 8.3 [13, 14]. The conditions chosen for simulation were identical to that used in the experiments: $T=800^{\circ} \mathrm{C}, P=1 \mathrm{~atm}$, molar feed ratio of $\mathrm{S} / \mathrm{C}=3$, and GHSV of $65,000 \mathrm{~h}^{-1}$. Upon assuming complete conversion of fuel, the equilibrium concentrations obtained for $\mathrm{H}_{2}, \mathrm{CO}, \mathrm{CO}_{2}$, and $\mathrm{CH}_{4}$ were about $78.34 \%, 9.86 \%$, $11.27 \%$, and $0.53 \%$, respectively. The simulations results observed here are similar to that reported in the literature for n-hexadecane reforming $[13,15]$.

Reformate compositions reported in Figure 7 are in good agreement with the equilibrium data predicted by the simulation. The hydrogen content in the reformate stream was slightly lower than the equilibrium conversion. It was observed from the experiments that traces of un-reacted liquid hydrocarbon fractions were seen in the condensate. This clearly suggests that conversion of fuel was not complete as assumed in the thermodynamic estimations.

In order to understand the synergy of the noble metals in the bimetallic formulations (specifically their sulfur tolerance), the time dependence of $\mathrm{H}_{2}$ yield in each case is shown in Figure 8.

Moreover, since kerosene contains $260 \mathrm{ppm}$ of sulfur, it is imperative to understand the difference in performance of these catalysts in terms of their behavior towards sulfur as well. For that purpose, the sulfur level $\left(\right.$ as $\left.\mathrm{H}_{2} \mathrm{~S}\right)$ in the exit 
TABLE 1: Comparison of performance of the mono- and bimetal-supported catalysts.

\begin{tabular}{lcccccc}
\hline & $\mathrm{Ru}$ & $\mathrm{Pd}$ & $\mathrm{Rh}$ & $\mathrm{RuPd}$ & $\mathrm{RuRh}$ & $\mathrm{RhPd}$ \\
\hline Max $\mathrm{H}_{2}$ yield (\%) & 79 & 84.4 & 87 & 86 & 88 & 89 \\
Duration (h) of steady level $\mathrm{H}_{2}$ yield & 51 & - & 55 & 68 & 88 & 75 \\
Time (h) to deactivate to $20 \% \mathrm{H}_{2}$ yield & 66 & 59 & 68 & 92 & 114 & 96 \\
\hline
\end{tabular}

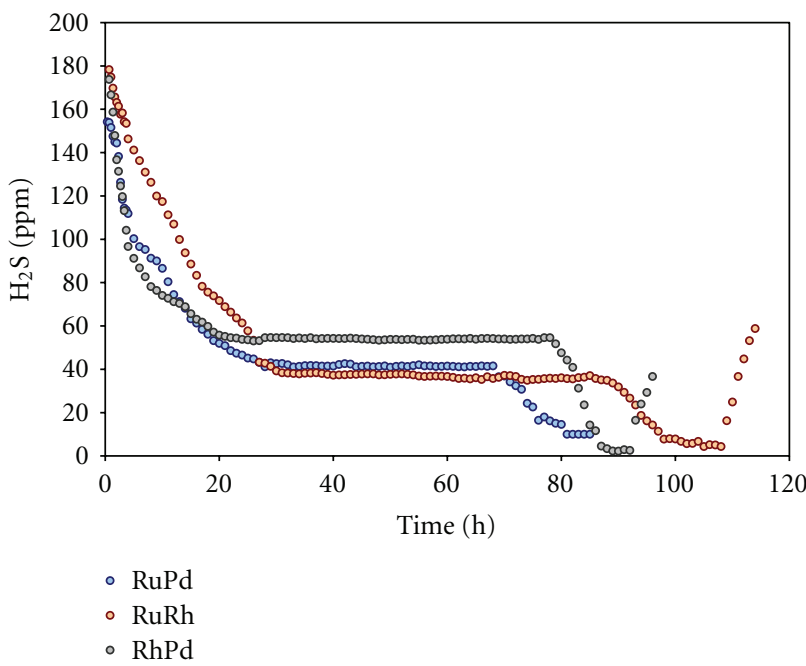

Figure 9: Trend in $\mathrm{H}_{2} \mathrm{~S}$ concentration profile for bimetallic catalysts with time on-stream.

stream was also monitored. The $\mathrm{H}_{2} \mathrm{~S}$ concentration profile as a function of time on-stream is shown in Figure 9.

Several interesting aspects emerge. For example, the sulfur level (in terms of $\mathrm{H}_{2} \mathrm{~S}$ ) drops rather quickly in the early stage of reformation, during which the hydrogen yield is somewhat lower, signifying that a steady-state has not reached yet. This initial $\mathrm{H}_{2} \mathrm{~S}$ drop (Figure 9) coupled with high-hydrogen generation rate (Figure 8) is indicative of the likelihood of preferential sulfur sorption by the cerium oxide support matrix. As stated in the previous sections and supported by the literature, ceria establishes a facile thermodynamic equilibrium with sulfur. This is evidenced in Figure 8 by the establishment of the steady state in the $\mathrm{H}_{2}$ generation profile in the first $30-36 \mathrm{~h}$ window. During this period, it is believed that one of the noble metals with higher affinity for sulfur is being partially sulfided by the remnant sulfur, leaving the other noble metal to continue the reforming activity. This minimizes the sulfur poisoning of the more noble metal, sparing it to continue to produce hydrogen. This hypothesis is strengthened by the observed trend in the sulfur tolerance and hydrogen generation by mono-metal-supported catalysts reported earlier [2] and by Figure 3 that compares the sulfur sorption characteristics of bimetal-supported ceria. During the second and longer steady-state period, concentration of sulfur in the reformate stream becomes almost stagnant; this is seen as the most active phase of the catalyst where the hydrogen yield is most optimum for extended period. This is followed by a sudden decrease in the $\mathrm{H}_{2} \mathrm{~S}$ concentration. It is hypothesized that this is due the sorption of sulfur by the second of the two noble metals. As the active sites on the second noble metal also begin to get sulfided, deactivation via sulfur poisoning ensues and the hydrogen yield starts to decline rapidly. A close examination of the profiles in Figure 8 with Figure 9 suggests that these two phenomena are almost synchronous. When both of the noble metals in respective formulations have been fully poisoned by sulfur, rapid reemergence of $\mathrm{H}_{2} \mathrm{~S}$ ensues. Interestingly, the slope of the rise in sulfur concentration with time (Figure 9) is identical in all the three cases, further fortifying the hypothesis laid out above.

From the foregoing discussion, it is amply clear that the choice of noble metal combination in the bimetallic formulations plays a vital and meaningful role in their performance. For instance, keeping with the inferior behavior of Pd-supported ceria catalyst in the mono-metal series [2], the bimetal formulations containing Pd (RuPd and RhPd) exhibited relatively shorter span where hydrogen production was steady. Furthermore, the duration of steady hydrogen production was higher in the case of $\operatorname{RhPd}(75 \mathrm{~h})$ than of RuPd $(68 \mathrm{~h})$. On the other hand, hydrogen generation was stable over the longest period $(88 \mathrm{~h})$ with RuRh that contained no Pd. It may be recalled that both RuRh and RhPd contain $1 / 2 \mathrm{wt} \%$ of $\mathrm{Rh}$ in each of them. Thus, the higher hydrogen yield and longer steady state in the case of RuRh and RhPd could be attributed to the presence of the common noble metal rhodium in them.

The average sulfur levels in the steady-state regions (flat zones) of Figure 8 as computed from the GC signals were 43.9, 37.9, and $53.7 \mathrm{ppm}$ for RuPd, RuRh, and RhPd, respectively, which re-enforces the benign role of $\mathrm{Ru}$ and $\mathrm{Rh}$ towards sulfur tolerance and could be explained in terms of the order of preference towards sulfur pick-up in the case of mono-metal catalysts [2]: $\mathrm{Pd}>\mathrm{Rh}>\mathrm{Ru}$. Thus, it could be stated that while Pd-alone formulations might not be very promising with regard to a steady and high-hydrogen yield from logistic fuels, the combination of $\mathrm{Pd}$ and/or $\mathrm{Ru}$ with $\mathrm{Rh}$ endows great degree of synergy, resulting thereby into formulations that are stable over long durations onstream and produce high quality reformate with high $\mathrm{H}_{2}$ fraction.

The postreformed samples were also subjected to systematic phase and microstructural analyses using XRD and TEM. Figure 10 shows the XRD patterns.

Except for the peak sharpening anticipated due to their prolonged on-stream exposure to fuel + steam, nothing unusual could be discerned from the XRD patterns of the postreformed catalysts; they remain identical to those for 


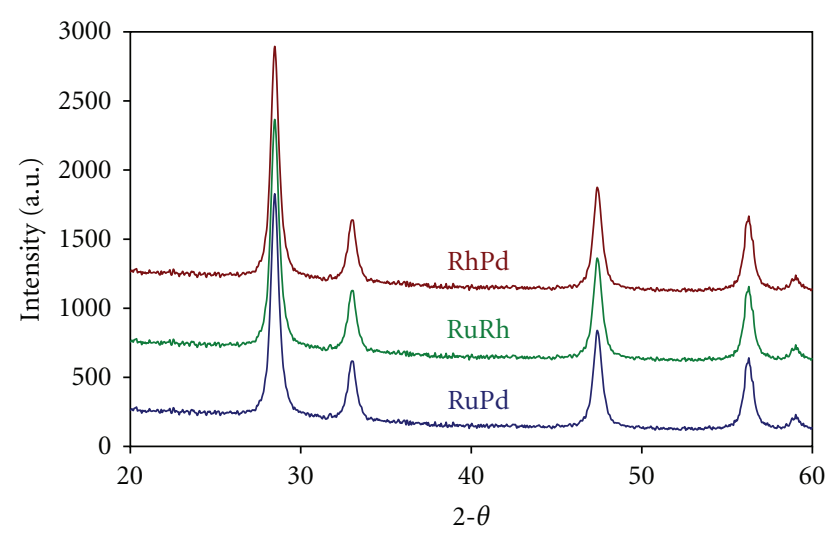

FIGURE 10: Comparative XRD patterns of the postreformed bimetallic catalysts.

as-prepared and the sulfided ones. They are also similar to those for the postreformed monometallic catalysts [2]. Thus, no new phases could be identified suggesting good phase integrity of the catalysts. Calculation from peak widths showed that the grain growth in them was also nominal. This resistance to sintering could be due to two major factors, (i) choice of the support material: GDC as opposed to $\alpha$ or $\gamma$-alumina and (ii) absence of $\mathrm{Ni}$ in the formulation which is typically the most commonly used catalyst component. Previous studies have indicated that sintering is a common problem in steam reforming catalysts containing noble metals ( $\mathrm{Rh}$ and/or $\mathrm{Ru}$ ) with $\mathrm{Ni}$ supported on $\mathrm{Al}_{2} \mathrm{O}_{3}$ catalysts [16-19]. Particularly, the carbon deposition is known to cause unacceptable level of pressure drop, thereby leading to particle disintegration and catalyst deactivation [15].

The TEM images of the postreformed bimetallic catalysts are shown in Figure 11. Due to low concentration, it was rather difficult to pinpointedly identify the individual noble metal in them. For the same reason, it was also difficult to distinguish the noble metals clearly using the EDS.

The TEM images suggest evidence of some agglomeration of the support matrix during reforming. Though there is evidence of grain growth and particle agglomeration, the dispersion of the noble metals is uniform. This explains why the activity of the catalyst was not compromised in spite of grain growth and agglomeration. This distinctive behavior of the bimetal-supported ceria formulations with regard to their tolerance to sulfur in a real logistic fuel such as kerosene has been studied in such a systematic fashion perhaps for the first time.

In the light of the experimental data discussed above, we propose the following phenomenological mechanism.

The hydrogen produced during the early stages of steamreforming acts as a hydrodesulfurization (HDS) precursor converting the organosulfur into $\mathrm{H}_{2} \mathrm{~S}$ [20-22]. See scheme 1.

Thiophene is used in scheme 1 for illustrative purpose. Credence to this mechanism is derived from Figure 9, where $\mathrm{H}_{2} \mathrm{~S}$ is detected from the very beginning of the reaction; the hydrogen sulfide thus formed then proceeds to react with nanoscale precious metals.

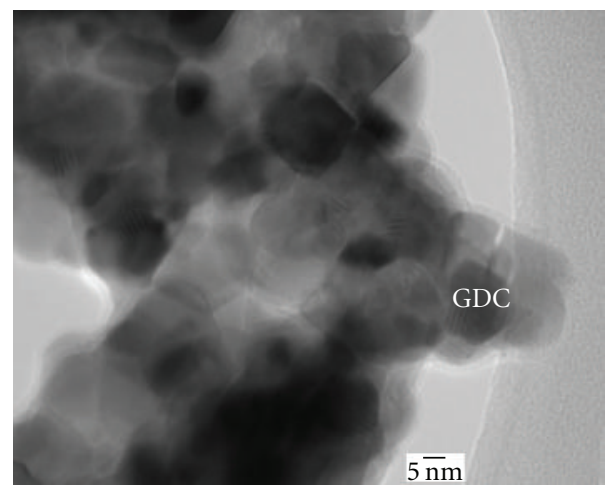

(a)

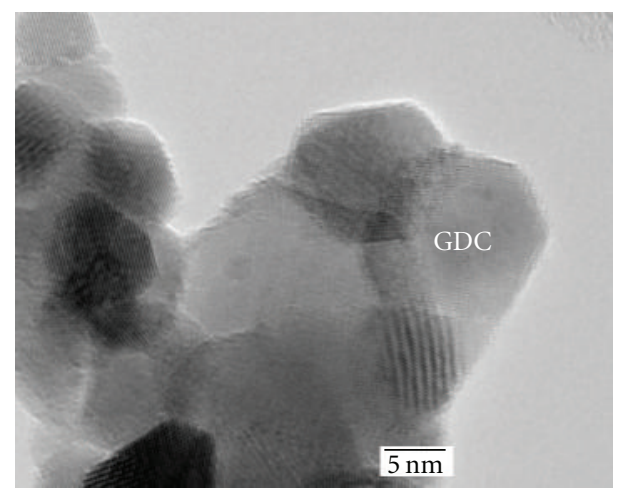

(b)

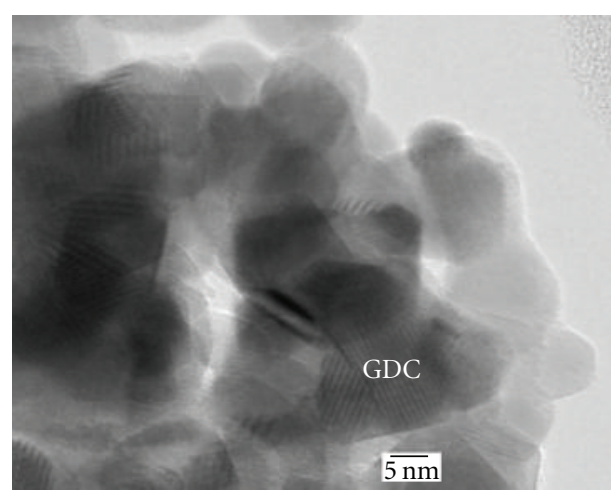

(c)

FIGURE 11: TEM image of the postreformed catalyst. (a) RuPd, (b) RuRh, and (c) RhPd.

In the case of palladium, the following reaction can be envisaged:

$$
\mathrm{Pd}+\mathrm{H}_{2} \mathrm{~S} \longrightarrow \mathrm{PdS}+\mathrm{H}_{2} .
$$

The rhodium sulfidation is a single-step process, where the most stable rhodium sulfide, $\mathrm{Rh}_{2} \mathrm{~S}_{3}$, is partially formed [20]

$$
2 \mathrm{Rh}+3 \mathrm{H}_{2} \mathrm{~S} \longrightarrow \mathrm{Rh}_{2} \mathrm{~S}_{3}+3 \mathrm{H}_{2} .
$$

Ruthenium binds sulfur as ruthenium sulfide, $\operatorname{RuS}_{x}[21]$ :

$$
\mathrm{Ru}+x \mathrm{H}_{2} \mathrm{~S} \longrightarrow \mathrm{RuS}_{x}+x \mathrm{H}_{2} .
$$




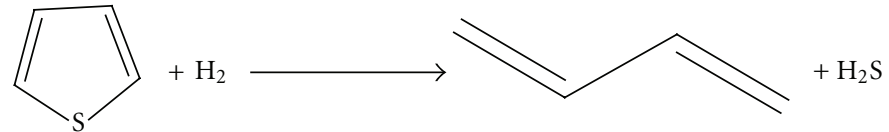

SCHEME 1

Here, the sulfidation could be viewed as a multistage process, as ruthenium compounds exhibit at least eight oxidation states, but the $+2,+3$, and +4 are the most common. One would expect these to be the most prevalent ones under conditions existing in reforming. Hence, one could anticipate the occurrence of one or all of the following reactions:

$$
\begin{gathered}
\mathrm{Ru}+\mathrm{H}_{2} \mathrm{~S} \longrightarrow \mathrm{RuS}+\mathrm{H}_{2}, \\
3 \mathrm{RuS} \longrightarrow \mathrm{Ru}_{2} \mathrm{~S}_{3}+\mathrm{Ru}, \\
\mathrm{Ru}+2 \mathrm{H}_{2} \mathrm{~S} \longrightarrow \mathrm{RuS}_{2}+2 \mathrm{H}_{2}, \\
2 \mathrm{Ru}+3 \mathrm{H}_{2} \mathrm{~S} \longrightarrow \mathrm{Ru}_{2} \mathrm{~S}_{3}+3 \mathrm{H}_{2}, \\
2 \mathrm{RuS} \longrightarrow \mathrm{RuS}_{2}+\mathrm{Ru}, \\
\mathrm{Ru}_{2} \mathrm{~S}_{3}+\mathrm{H}_{2} \mathrm{~S} \longrightarrow 2 \mathrm{RuS}_{2}+\mathrm{H}_{2} .
\end{gathered}
$$

The transition of the atomic ratio of ruthenium to sulfur from $1: 1$ (in RuS) to $1: 1.5\left(\right.$ in $\left.\mathrm{Ru}_{2} \mathrm{~S}_{3}\right)$ to $1: 2\left(\right.$ in $\mathrm{RuS}_{2}$ ) as outlined in the above scheme is substantiated by the observation made by Wojciechowska et al. [22] and Chianelli [23] and others [24] that the sulfides of ruthenium exhibit exceptional HDS activity. A similar conclusion was arrived at by Ishiguro et al. [25] who examined the evolution of ruthenium sulfide nanoclusters on titania support.

At this juncturee it is relevant to ask the question: is the sulfidation of the precious metals alone responsible for the observed sulfur tolerance? The answer is no; while the scheme outlined above is feasible, it cannot possibly be the primary mechanism. Were this true, the sustained high hydrogen yields over long period as recorded in Figure 7 or 8 would not be possible. It stands to reason that the outstanding performance of the formulations developed in this work is borne out of the fact that there is another mechanism for sulfur resistance.

It is well known that ceria itself is capable of forming an oxysulfide [26-29]. Therefore, in reducing environments, due cognizance, should be given to the highly favorable thermodynamics of $\mathrm{CeO}_{2}-\mathrm{H}_{2}-\mathrm{H}_{2} \mathrm{~S}$ system

$$
\begin{gathered}
\mathrm{CeO}_{2}(\mathrm{~s})+(2-n) \mathrm{H}_{2}(\mathrm{~g}) \\
\longrightarrow \mathrm{CeO}_{\mathrm{n}}(\mathrm{s})+(2-n) \mathrm{H}_{2} \mathrm{O}(\mathrm{g}), \\
\mathrm{CeO}_{n}(\mathrm{~s})+\mathrm{H}_{2} \mathrm{~S}(\mathrm{~g})+(2 n-3) \mathrm{H}_{2}(\mathrm{~g}) \\
\longrightarrow \mathrm{Ce}_{2} \mathrm{O}_{2} \mathrm{~S}\left(\mathrm{~s}+2(n-1) \mathrm{H}_{2} \mathrm{O}(\mathrm{g})\right) .
\end{gathered}
$$

It should be noted that for ceria sulfidation, two things ought to happen: reduction of $\mathrm{Ce}^{4+}$ followed by sulfidation

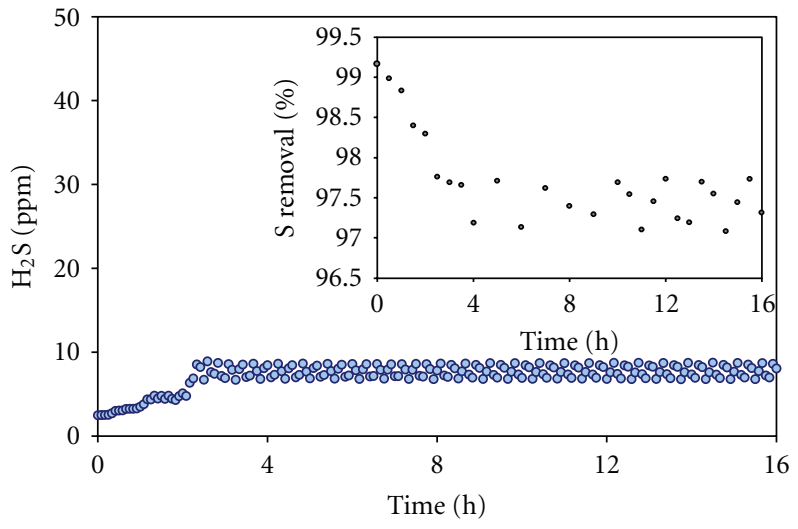

FIGURE 12: Evidence of sulfur pickup propensity of pure GDC at $800^{\circ} \mathrm{C}$.

in a reducing environment; cerium is in 3+ oxidation state in $\mathrm{Ce}_{2} \mathrm{O}_{2} \mathrm{~S}$.

To clarify the debate whether this is happening in our case where the precious metals are supported on ceria matrix, an independent sulfidation experiment on GDC alone was performed using a stream of $90 \% \mathrm{H}_{2}, 9.97 \% \mathrm{~N}_{2}$, and $300 \mathrm{ppm} \mathrm{H}_{2} \mathrm{~S}$ at $800^{\circ} \mathrm{C}$ for $16 \mathrm{~h}$, simulating the reducing conditions and sulfur level prevailing in the case of original fuel (kerosene). The time dependence of the sulfur level in the exit stream is shown in Figure 12; the extent of sulfur picked up by GDC during the same period is shown in the inset.

As can be seen clearly, sulfur scavenging appears to be almost $100 \%$ from the very beginning of the simulated reaction, and it reaches steady-state rather quickly and its concentration in the exit stream hovers around $8 \pm 1 \mathrm{ppm}$ for the next $14 \mathrm{~h}$. This unequivocally establishes that the primary sulfur tolerance in the steam reforming of kerosene comes from the inherent and thermodynamically feasible sulfurizability of the ceria support matrix; by virtue of this, the noble metals are spared sulfur attack and remain active in the reforming of the sulfur-denuded fuel leading to highhydrogen yield.

At this juncture, it is worth pointing that the most extensively employed inert catalytic support, namely, alumina ( $\alpha$ or $\gamma$ ) is not endowed with such unique capability, which explains the short-term activity of such catalysts, even those which have far higher loading of noble metals. In the present case, on the contrary, the support and the combination of two noble metals accentuate the overall sulfur tolerance, which in turn led to the generation of a highly $\mathrm{H}_{2}$-rich reformate. The duration of steady-state-hydrogen yield was in turn an artifact of relative susceptibility of a given noble metal in the bimetallic formulations. 


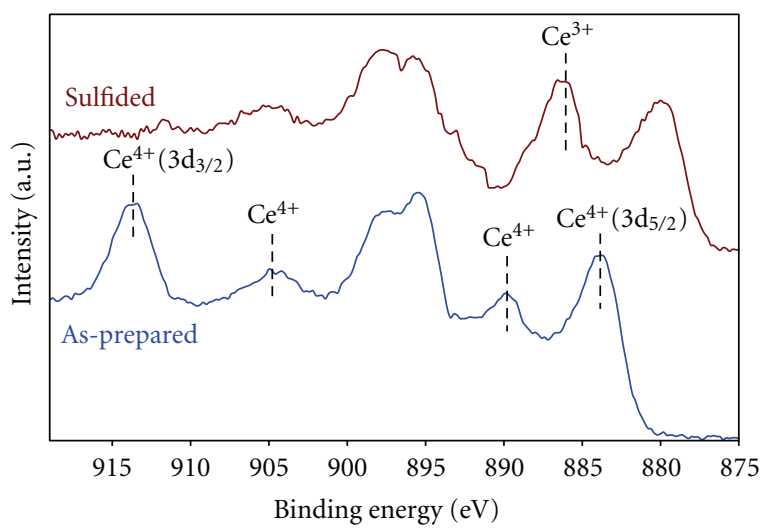

FIGURE 13: Comparison of the XPS signature of virgin GDC sample with that sulfided at $800^{\circ} \mathrm{C}$ for $16 \mathrm{~h}$ in a gas stream containing 300 ppm $\mathrm{H}_{2} \mathrm{~S}$.

Systematic XPS characterization was carried out on the as-prepared and sulfided GDC samples and the results are shown in Figure 13.

The XPS investigation indicates that the $\mathrm{Ce}^{3+}$ and $\mathrm{Ce}^{4+}$ species can be differentiated with distinct line shapes corresponding to various final states. As can be readily seen from this figure, the intensity of the peaks around $\sim 914$, $905,897,890$, and $884 \mathrm{eV}$ in the as-prepared sample, which correspond to $\mathrm{Ce}^{4+}$ oxidation state, decreased, and those around $\sim 886$ and $880 \mathrm{eV}$ in the sulfided samples increased; the later correspond to $\mathrm{Ce}$ in $3+$ oxidation state. This implies that in the sulfided sample, both $\mathrm{Ce}^{4+}$ and $\mathrm{Ce}^{3+}$ oxidation states coexist. The slight shifts seen in the peak positions of the virgin and the sulfided samples could be ascribed to difference in the local atomic environment of $\mathrm{Ce}$ in the gadolinia-doped ceria (GDC) as opposed to pure ceria $\left(\mathrm{CeO}_{2}\right)$, on which the XPS data are generally acquired and/or reported [30-32].

X-ray photoelectron spectra were also collected on respective bimetal-supported catalysts after steam reforming of kerosene on them. The data analyses based on the binding energy unequivocally showed that ruthenium was present in $4+$ oxidation state $\left(\mathrm{Ru}\left(3 \mathrm{~d}_{3 / 2}\right) ; 284 \mathrm{eV}\right)[2,33]$. No peak at $280 \mathrm{eV}$ corresponding to $\mathrm{Ru}\left(3 \mathrm{~d}_{5 / 2}\right)$ in metallic state was present [33], suggesting that the noble metal did not undergo reduction to zerovalent elemental $\mathrm{Ru}$ during reformation of kerosene. Peaks at 336 and $342 \mathrm{eV}$ belonging to $\mathrm{Pd}\left(3 \mathrm{~d}_{5 / 2}\right)$ and $\operatorname{Pd}\left(3 \mathrm{~d}_{3 / 2}\right)$, respectively, indicated that $\mathrm{Pd}$ in the postreformed catalyst is in Pd (II) oxidation state [2,34]. Similarly, the final oxidation state of rhodium in Rh-based sample is $3+$ denoted by two peaks at 306.4 and $312 \mathrm{eV}$ and corresponds to $\operatorname{Rh}\left(3 \mathrm{~d}_{5 / 2}\right)$ and $\operatorname{Rh}\left(3 \mathrm{~d}_{3 / 2}\right)$, respectively $[2,35]$.

The combined chromatographic, microscopic, and spectroscopic data provide unequivocal evidence that ceria support does participate in sulfur uptake from the fuel, thereby allowing the precious metals to perform actively as the fuel reforming components. Also, as discussed above, the increase in sulfur level in the exit stream and the decline in hydrogen yield at the end of steady-state regime, seen in Figures 7 and 8, respectively, marks the eventual sulfidation of both the precious metals in the catalyst formulations employed in this work.

From the foregoing discussion based on the cumulative chromatographic, microscopic, and spectroscopic data, it is apparent that there exists a definite synergistic correlation between the behaviors of various noble metals when present in the presence of one another. In order to understand this aspect, one could invoke stepwise sulfidation of various components of the catalyst, which is in line with the observed reforming behavior in these materials. For example, there is unequivocal evidence that ceria support does participate in sulfur uptake from the fuel, thereby allowing the precious metals to perform actively as the fuel reforming components. It was shown that the primary sulfur tolerance of the catalysts comes from the excellent sulfurizability aspect of the host matrix, viz., $\mathrm{CeO}_{2}$. The noble metal(s) sulfidation then ensues, progresses and attains completion in the steadystate regime of hydrogen generation in high yield. Also, the increase in sulfur level in the exit stream with a concomitant decline in hydrogen yield at the end of steady-state regime marks the eventual sulfidation of both the precious metals in the catalyst formulations.

Based on these self-supporting experimental evidences, a phenomenological mechanism operative in the steamreforming of a sulfur-laden logistic fuel (such as kerosene, used in this case) on the bimetallic catalysts emerges. The mechanism essentially involves a sequential combination of the reactions shown in (2) through (8). This general multistage scheme is reflected in the sequence shown in Figure 14.

In the light of the foregoing discussion, several multifunctional aspects of the catalysts developed in this work become evident.

The nanostructured bimetallic catalysts performed significantly better than their monometallic counterparts. Reasonably, high-hydrogen yield, longer duration of steadystate, and lower $\mathrm{H}_{2} \mathrm{~S}$ concentration in the exit was achieved. Some of the key features of sulfidation and reforming experiments with this series are as follows.

(a) Presence of ruthenium and/or rhodium in formulations containing palladium improved their sulfur tolerance and enhanced their catalytic activity significantly.

(b) Rhodium-based formations gave higher hydrogen yields.

(c) Presence of ruthenium certainly added stability of the catalysts.

(d) Cooperative synergy exists between the noble metals in each of these formulations.

(e) Definite correlation exists between the nature of the noble metal with hydrogen production and sulfur tolerance.

It should be pointed out that the performance of these formulations could be further enhanced by using trimetal combinations; these findings have recently been reported [36]. 


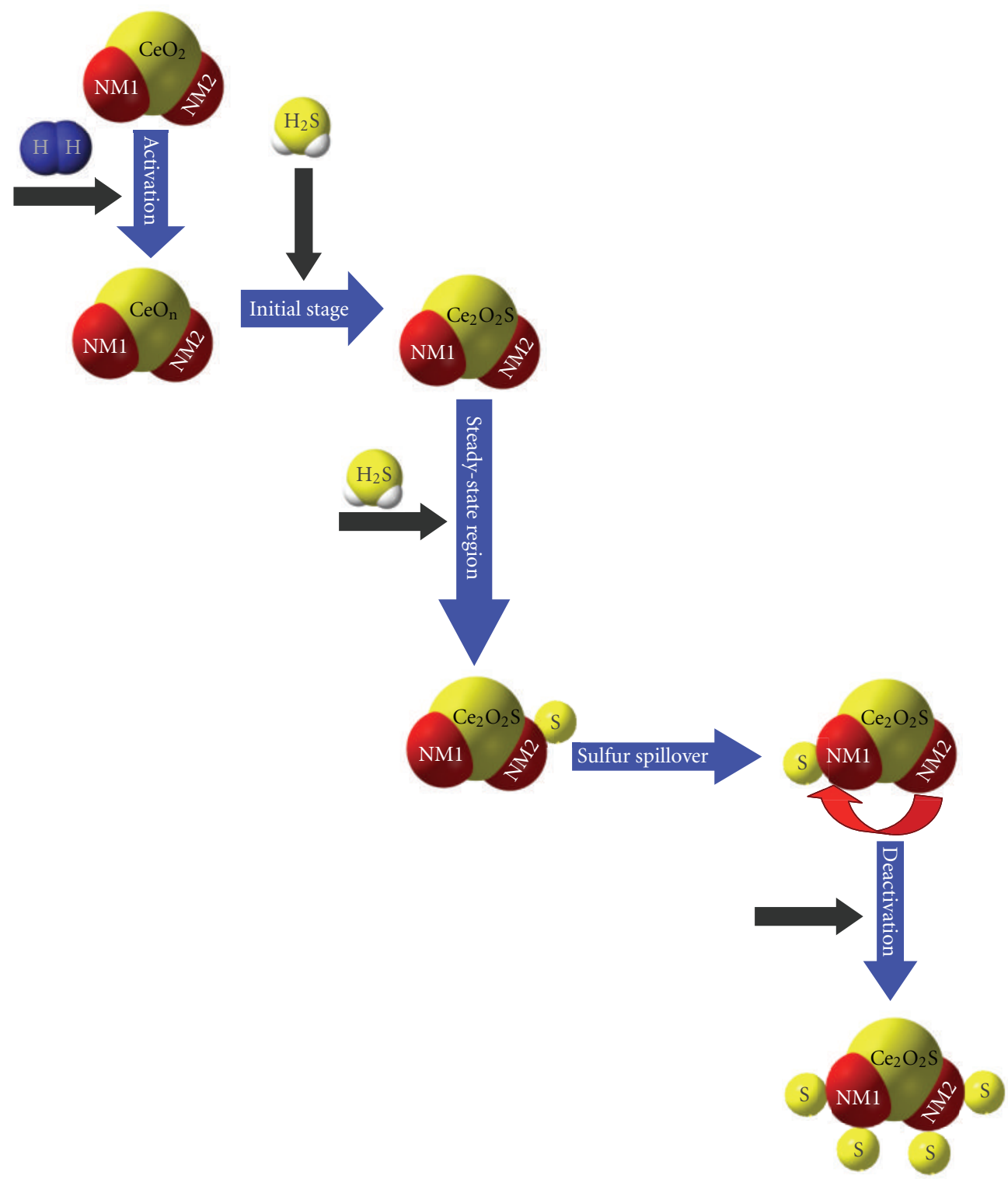

FIGURE 14: Phenomenological mechanism operative in the bimetal-supported catalysts.

\section{Conclusion}

A new family of high-performance bimetal-supported ceria nanocatalysts has been developed and systematically characterized with respect to their structural, microstructural and sulfur tolerance aspects. Steam reforming of kerosene at $800^{\circ} \mathrm{C}$ and atmospheric pressure with steam-tocarbon (S/C) ratio equals to 3.0 on these formulations produces hydrogen-rich reformates over long durations before deactivation sets in, which is rather slow and monotonic than sudden and precipitous. The difference in the behavior of various formulations is explained in terms of the inherent ability of the ceria support to pick up sulfur in the stream. This together with the synergistic sulfidation propensity of the precious metals dispersed on ceria is the reason behind excellent performance of these formulations. By virtue of this capability, the bimetallic formulations containing low levels of loading on each active metal (total combined NM loading $=1 \mathrm{wt} . \%$ ). The catalyst deactivation appears mainly due to the sulfur poisoning rather than carburization (coke formation) based on the absence of noticeable level of elemental carbon in high-resolution microscopic images in the postreformed samples.

\section{References}

[1] Y. Lu, J. Chen, Y. Liu, Q. Xue, and M. He, "Highly sulfurtolerant $\mathrm{Pt} / \mathrm{Ce}_{0.8} \mathrm{Gd}_{0.2} \mathrm{O}_{1.9}$ catalyst for steam reforming of liquid hydrocarbons in fuel cell applications," Journal of Catalysis, vol. 254, no. 1, pp. 39-48, 2008.

[2] A.-M. Azad and S. Desikan, "A phenomenological study on the synergistic role of precious metals in the steam reforming of logistic fuels on monometal supported catalysts," Advances in Materials Science and Engineering, vol. 2010, Article ID 681574, 15 pages, 2010. 
[3] A. Trovarelli, Ed., Catalysis by Ceria and Related Materials, vol. 2, Imperial College Press, London, UK, 2002.

[4] Handbook of Aviation Fuel Properties, Coordinating Research Council, Atlanta, Ga, USA, 1983.

[5] M. Mogensen, N. M. Sammes, and G. A. Tompsett, "Physical, chemical and electrochemical properties of pure and doped ceria," Solid State Ionics, vol. 129, no. 1, pp. 63-94, 2000.

[6] M. Funabiki, T. Yamada, and K. Kayano, "Auto exhaust catalysts," Catalysis Today, vol. 10, no. 1, pp. 33-43, 1991.

[7] S. Tagliaferri, R. A. Köppel, and A. Baiker, "Influence of rhodium- and ceria-promotion of automotive palladium catalyst on its catalytic behaviour under steady-state and dynamic operation," Applied Catalysis B, vol. 15, no. 3-4, pp. 159-177, 1998.

[8] A.-M. Azad and M. J. Duran, "Development of ceriasupported sulfur tolerant nanocatalysts: Rh-based formulations," Applied Catalysis A, vol. 330, no. 1-2, pp. 77-88, 2007.

[9] A.-M. Azad, M. J. Duran, A. K. McCoy, and M. A. Abraham, "Development of ceria-supported sulfur tolerant nanocatalysts: Pd-based formulations," Applied Catalysis A, vol. 332, no. 2, pp. 225-236, 2007.

[10] A. C. McCoy, M. J. Duran, A. M. Azad, S. Chattopadhyay, and M. A. Abraham, "Performance of sulfur tolerant reforming catalysts for production of hydrogen from jet fuel simulants," Energy \& Fuels, vol. 21, no. 6, pp. 3513-3519, 2007.

[11] ICDD card \# 75-0162.

[12] A. Kataria, P. Ayyappan, and M. Abraham, "Effective sulfur tolerant catalyst for steam reforming of jet fuel," in Proceedings of the 2007 AIChE Annual Meeting, USA, November 2007.

[13] D. H. Kim, J. S. Kang, Y. J. Lee et al., "Steam reforming of n-hexadecane over noble metal-modified Ni-based catalysts," Catalysis Today, vol. 136, no. 3-4, pp. 228-234, 2008.

[14] D. J. Moon, J. W. Ryu, S. D. Lee, B. G. Lee, and B. S. Ahn, "Nibased catalyst for partial oxidation reforming of iso-octane," Applied Catalysis A, vol. 272, no. 1-2, pp. 53-60, 2004.

[15] J. Thormann, L. Maier, P. Pfeifer, U. Kunz, O. Deutschmann, and K. Schubert, "Steam reforming of hexadecane over a $\mathrm{Rh} / \mathrm{CeO}_{2}$ catalyst in microchannels: experimental and numerical investigation," International Journal of Hydrogen Energy, vol. 34, no. 12, pp. 5108-5120, 2009.

[16] S. L. Lakhapatri and M. A. Abraham, "Deactivation due to sulfur poisoning and carbon deposition on $\mathrm{Rh}-\mathrm{Ni} / \mathrm{Al}_{2} \mathrm{O}_{3}$ catalyst during steam reforming of sulfur-doped n-hexadecane," Applied Catalysis A, vol. 364, no. 1-2, pp. 113-121, 2009.

[17] K. O. Christensen, D. Chen, R. Lødeng, and A. Holmen, "Effect of supports and Ni crystal size on carbon formation and sintering during steam methane reforming," Applied Catalysis A, vol. 314, no. 1, pp. 9-22, 2006.

[18] T. Numaguchi, K. Shoji, and S. Yoshida, "Hydrogen effect on $\alpha-\mathrm{Al}_{2} \mathrm{O}_{3}$ supported $\mathrm{Ni}$ catalyst for steam methane reforming reaction," Applied Catalysis A, vol. 133, no. 2, pp. 241-262, 1995.

[19] J. J. Strohm, J. Zheng, and C. Song, "Low-temperature steam reforming of jet fuel in the absence and presence of sulfur over Rh and Rh-Ni catalysts for fuel cells," Journal of Catalysis, vol. 238, no. 2, pp. 309-320, 2006.

[20] M. Wojciechowska, M. Pietrowski, and S. Lomnicki, "Novel supported catalyst for hydrodesulfurization reaction," Chemical Communications, no. 5, pp. 463-464, 1999.

[21] T. A. Pecoraro and R. R. Chianelli, "Hydrodesulfurization catalysis by transition metal sulfides," Journal of Catalysis, vol. 67, no. 2, pp. 430-445, 1981.

[22] M. Wojciechowska, M. Pietrowski, B. Czajka, and S. Lomnicki, "Influence of activation and the HDS reaction on the structure of magnesium fluoride-supported $\mathrm{Ru}$ catalysts derived from ruthenium chloride hydrate," Catalysis Letters, vol. 87, no. 3-4, pp. 153-157, 2003.

[23] R. R. Chianelli, "Periodic trends transition metal sulfide catalysis: intuition and theory," Oil and Gas Science and Technology, vol. 61, no. 4, pp. 503-513, 2006.

[24] "Imaging of catalyst nanoparticles," http://www.chemistry. bnl.gov/nanocatalysis/research/imaging/imaging.htm.

[25] A. Ishiguro, T. Nakajima, T. Iwata et al., "Nanoparticles of amorphous ruthenium sulfide easily obtainable from a $\mathrm{TiO}_{2}$ supported hexanuclear cluster complex $\left[\mathrm{Ru}_{6} \mathrm{C}(\mathrm{CO})_{16}\right]^{-2}$ : a highly active catalyst for the reduction of $\mathrm{SO}_{2}$ with $\mathrm{H}_{2}$," Chemistry, vol. 8, no. 14, pp. 3260-3268, 2002.

[26] V. Meng, D. A. R. Kay et al., "High tech ceramics," in Proceedings of the Proceedings of the World Congress on High Tech Ceramics, the 6th International Meeting on Modern Ceramic Technologies, P. Vincenzini, Ed., Elsevier, Milan, Italy, June 1986.

[27] R. M. Ferrizz, R. J. Gorte, and J. M. Vohs, "Determining the $\mathrm{Ce}_{2} \mathrm{O}_{2} \mathrm{~S}-\mathrm{CeO}_{x}$ phase boundary for conditions relevant to adsorption and catalysis," Applied Catalysis B, vol. 43, no. 3, pp. 273-280, 2003.

[28] K. Yi, Ceria-zirconia oxide high temperature desulfurization sorbent, Ph.D. thesis, Louisiana State University, 2004.

[29] R. S. Kempegowda, N. Laosiripojana, and S. Assabumrungrat, "High temperature desulfurization over nano-scale high surface area ceria for application in SOFC," Korean Journal of Chemical Engineering, vol. 25, no. 2, pp. 223-230, 2008.

[30] Z. Wu, D. Huang, X. Yang et al., "Identification of induced reaction during XPS depth profile measurements of $\mathrm{CeO}_{2} / \mathrm{Si}$ films grown by ion beam epitaxy," Vacuum, vol. 49, no. 2, pp. 133-137, 1998.

[31] H. Ono, A. Iwase, N. Ishikawa, Y. Baba, and N. Hirao, "Study of high energy ion-radiation effects in $\mathrm{CeO}_{2}$ by X-ray photoelectron spectroscopy," in Photon Factory Activity Report \#27, 27A/2007G058, p. 138, 2008.

[32] E. Bêche, P. Charvin, D. Perarnau, S. Abanades, and G. Flamant, "Ce 3d XPS investigation of cerium oxides and mixed cerium oxide $\left(\mathrm{Ce}_{x} \mathrm{Ti}_{y} \mathrm{O}_{z}\right)$," Surface and Interface Analysis, vol. 40, no. 3-4, pp. 264-267, 2008.

[33] J. F. Moulder, W. F. Stickle, P. E. Sobol, K. D. Bomben, J. Chastain, and R. C. King, Handbook of X-Ray Photoelectron Spectroscopy, Physical Electronics, Eden Prairie, Minn, USA, 1995.

[34] C. Mun, J. J. Ehrhardt, J. Lambert, and C. Madic, "XPS investigations of ruthenium deposited onto representative inner surfaces of nuclear reactor containment buildings," Applied Surface Science, vol. 253, no. 18, pp. 7613-7621, 2007.

[35] A. Gayen, K. R. Priolkar, P. R. Sarode et al., "Solid solution formation in combustion-synthesized catalyst studied by XRD, TEM, XPS, and EXAFS," Chemistry of Materials, vol. 16, no. 11, pp. 2317-2328, 2004.

[36] A.-M. Azad and D. Sundararajan, "A phenomenological study on the synergistic role of precious metals and the support in the steam reforming of logistic fuels on tri-metal supported catalysts," Advances in Materials Science and Engineering, vol. 2010, Article ID 681574, 12 pages, 2010. 

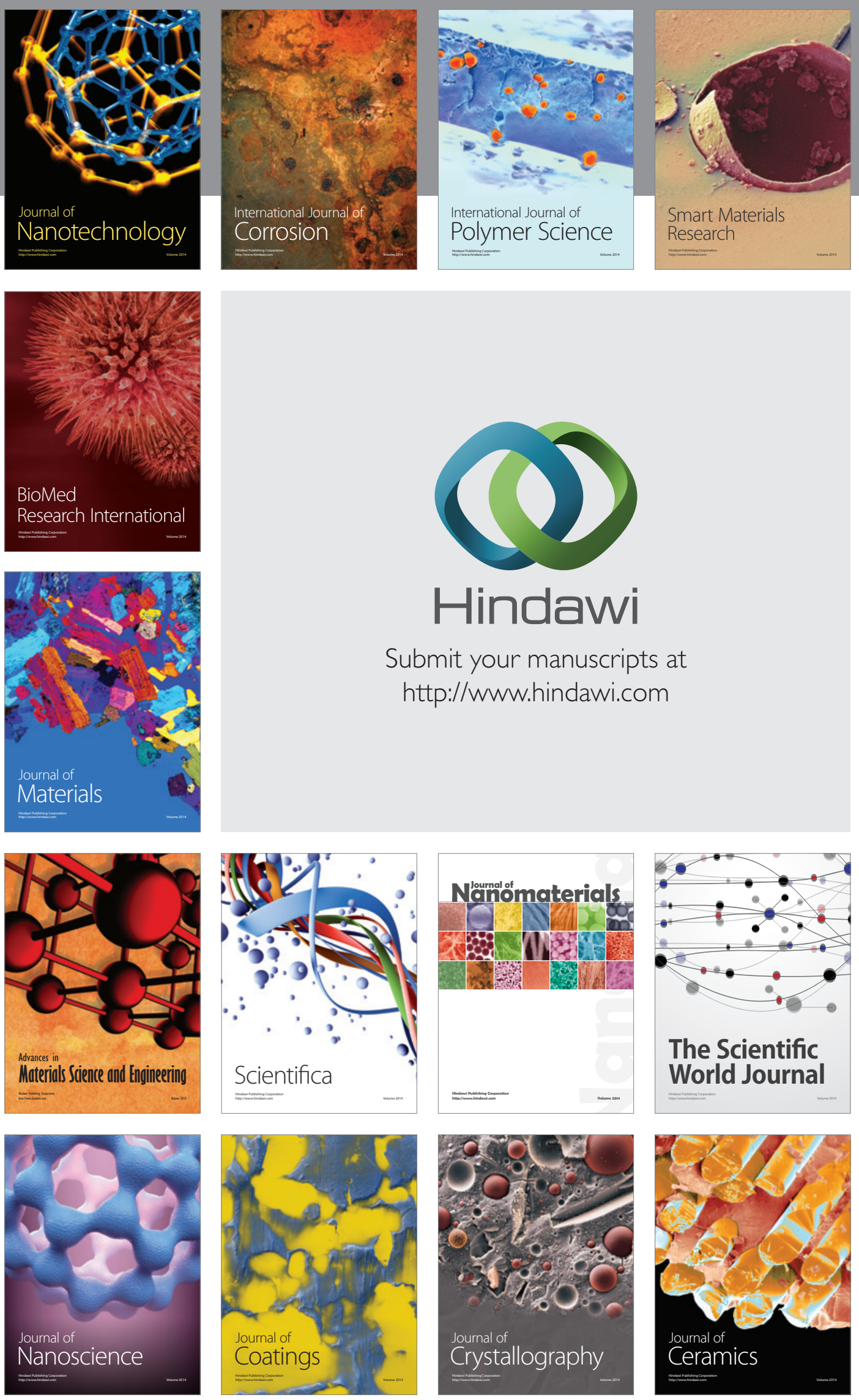

The Scientific World Journal

Submit your manuscripts at

http://www.hindawi.com

\section{World Journal}

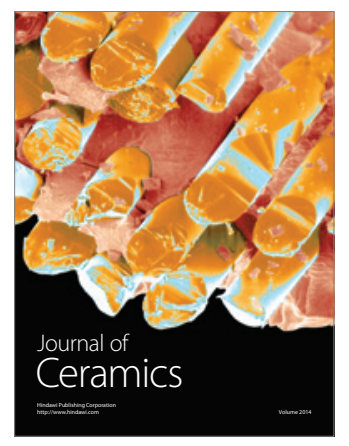

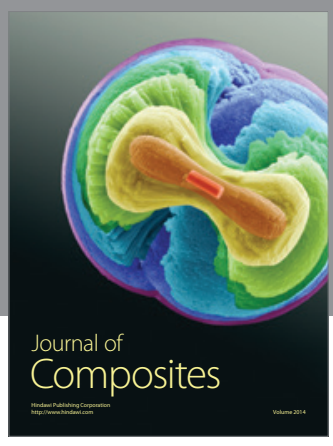
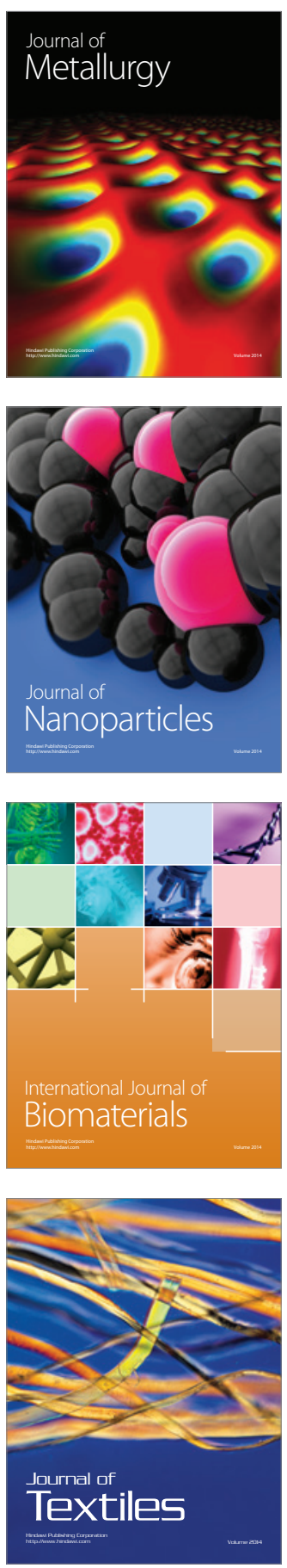